\title{
Update from the World Symposium on Pulmonary Hypertension 2018: does the new hemodynamic definition of pediatric pulmonary hypertension have an impact on treatment strategies?
}

\author{
Astrid E. Lammers ${ }^{1}$, Christian Apitz ${ }^{2}$ \\ ${ }^{1}$ Department of Pediatric Cardiology and Department of Cardiology III-Adult Congenital and Valvular Heart Disease, University Hospital Münster, \\ Münster, Germany; ${ }^{2}$ Division of Pediatric Cardiology, University Children's Hospital Ulm, Ulm, Germany \\ Correspondence to: Astrid Lammers, MD. Department of Pediatric Cardiology and Department of Cardiology III-Adult Congenital and Valvular Heart \\ Disease, University Hospital Münster, Albert-Schweitzer-Campus 1, 48149 Münster, Germany. Email: Astrid.Lammers@ukmuenster.de.
}

\begin{abstract}
Pediatric pulmonary arterial hypertension $(\mathrm{PAH})$ is a progressive life-threatening disease of the pulmonary vasculature and is defined as an elevation of the mean pulmonary arterial pressure. Before the 6th World Symposium on Pulmonary Hypertension (WSPH) in 2018, pulmonary hypertension (PH) used to be defined as a mean pulmonary artery pressure (mPAP) of $\geq 25 \mathrm{mmHg}$. On the WSPH a revised hemodynamic definition of $\mathrm{PH}$ was introduced lowering the threshold for a normal mPAP from $<25$ to $<21 \mathrm{mmHg}$. The Pediatric Task Force chose to follow this newly proposed definition of $\mathrm{PH}$ in order to speak a uniform language and facilitate transition to adult services. In this opinion paper we discuss the rationale behind the new $\mathrm{PH}$ definition and the impact on pediatric $\mathrm{PH}$. We conclude, that to date, there is no evidence in children, suggesting that this decrease of threshold for $\mathrm{PH}$ warrants any further measures than clinical outpatient-follow-up. Hitherto, the new definition does not impact on currently applicable treatment strategies in children with $\mathrm{PH}$.
\end{abstract}

Keywords: Pediatric pulmonary hypertension (pediatric PH); World Symposium on Pulmonary Hypertension 2018 (WSPH 2018); definition; (targeted) advanced therapy

Submitted Apr 02, 2020. Accepted for publication Apr 29, 2020.

doi: $10.21037 / \mathrm{cdt}-20-412$

View this article at: http://dx.doi.org/10.21037/cdt-20-412

\section{Introduction}

Pulmonary hypertension (PH) is characterized by an elevation of the pulmonary arterial pressure and is associated with different underlying diseases affecting the pulmonary vasculature. While there is increased evidence for genetic factors playing a causative role, predisposing an individual to the phenotype and development of $\mathrm{PH}$, underlying etiologies, triggers and driving factors vary. Etiologies in children comprise pathologies of the lung parenchyma or interstitial changes and uncorrected cardiac shunt lesions with increased pulmonary blood flow, that may lead to pulmonary vascular disease. In addition, structural lesions of the left heart or myocardial dysfunction can potentially cause postcapillary $\mathrm{PH}$.
The most frequent forms of $\mathrm{PH}$ in childhood are idiopathic pulmonary arterial hypertension (IPAH)/ hereditary pulmonary hypertension $(\mathrm{HPAH})$ and PAH associated with congenital heart disease (PAH-CHD) (1).

According to international guidelines, $\mathrm{PH}$ used to be defined as elevation of the mean pulmonary artery pressure $(\mathrm{mPAP}) \geq 25 \mathrm{mmHg}$. Due to variability in pulmonary hemodynamics during the postnatal adaptation process, pediatric $\mathrm{PH}$ was formerly defined as $\mathrm{mPAP} \geq 25 \mathrm{mmHg}$ in children $>3$ months of age. In pediatric $\mathrm{PH}$, particularly in patients with associated $\mathrm{PH}-\mathrm{CHD}$, it is recommended to use the indexed pulmonary vascular resistance (PVRI) to assess the presence of pulmonary vascular hypertensive disease (PVHD), defined as PVRI $\geq 3$ wood units $\times \mathrm{m}^{2}$ $\left(\mathrm{WU} \times \mathrm{m}^{2}\right)$ (Table 1). 
Table 1 Definitions of $\mathrm{PH}$ in children and adolescents

\begin{tabular}{|c|c|}
\hline $\mathrm{PH}$ & mPAP $>20 \mathrm{mmHg}$ in children $>3$ months at sea level \\
\hline Combined pre- and postcapillary $\mathrm{PH}$ & mPAP >20 mmHg; PAWP or LVEDP >15 mmHg; PVRI $\geq 3$ WU $\times \mathrm{m}^{2}$ \\
\hline \multicolumn{2}{|c|}{$\begin{array}{l}\text { Modified according to reference (2). "mPAP-mLAP or PAWP, PH, pulmonary hypertension; mPAP, mean pulmonary artery pressure; PAH, } \\
\text { pulmonary arterial hypertension; PAWP, pulmonary artery wedge pressure; LVEDP, left ventricular end diastolic pressure; PVRI, pulmonary } \\
\text { vascular resistance index; TPG, transpulmonary pressure gradient; WU, wood units"; PHVD, pulmonary hypertensive vascular disease; } \\
\text { mLAP, mean left atrial pressure. ", Traditional unit of vascular resistance. }\end{array}$} \\
\hline
\end{tabular}

\section{The updated PH definition}

During the latest World Symposium on Pulmonary Hypertension (WSPH) 2018 in Nice, it was proposed, that the mPAP threshold to define $\mathrm{PH}$ should be lowered from $\geq 25$ to $>20 \mathrm{mmHg}(3)$.

Additionally to the criterion to determine precapillary $\mathrm{PH}$ of a left ventricular end diastolic pressure (LVEDP) or pulmonary capillary wedge pressure (PCWP) $\leq 15 \mathrm{mmHg}$, the PVRI as adjunct variable was added to this definition (4).

The rationale for lowering the mPAP threshold is based on register studies of adult $\mathrm{PH}$ patients which revealed higher mortality yet with these lower mPAP levels $(5,6)$.

This new definition (mPAP $>20 \mathrm{mmHg}$ ) has also been accepted by the Pediatric Task Force of the WSPH, in order to speak a common language and facilitate transition to adult services (4). However this was not uniformly welcomed by all pediatric cardiologists as concerns existed that the new definition may lead to overdiagnosis and overtreatment of $\mathrm{PH}$.

The new definition has already been appreciated and found entry to the updated consensus document of the "European Pediatric Pulmonary Vascular Disease Network" published in 2019 (2). However, to date there are no pediatric data, to suggest that a mild elevation of the mPAP of $21-24 \mathrm{mmHg}$ (according to the new definition) has similar impact in children as in adults $(2,4)$.

In most children, who are diagnosed even at a young age with idiopathic PH, mPAPs do well exceed these values anyhow. Other pediatric $\mathrm{PH}$ subgroups may present with lower levels of mPAP (21-24 $\mathrm{mmHg}$ ), who are now being categorized with the diagnosis of $\mathrm{PH}$. This may apply particularly for infants with chronic lung disease (CLD)/ bronchopulmonary dysplasia (BPD), who can present with variable levels of $\mathrm{PH}$ severity. But even for those children, to date there is no data to suggesting a necessity to treat patients with mPAP $<25 \mathrm{mmHg}$. Treatment initiation at these lower levels of $\mathrm{PH}$ warrants careful judgement and consideration of comorbidities.

Particularly children with an associated congenital cardiac shunt (e.g., atrial- or ventricular septal defect or persistent arterial duct) may show a prolonged period of cardiopulmonary adaptation with a slower decrease in PVR compared to infants without a shunt defect. Those infants with a congenital heart defect and a significant shunt benefit most from a timely intervention and shunt closure, to abolish the extra strain on the pulmonary vasculature, avoid PVHD progression due to an increased pulmonary blood flow. If other risk factors for $\mathrm{PH}$ and an increased likelihood of persistence of problems are present, that could at least in part contribute to high pulmonary artery pressures, fenestrated closure should be considered.

Only a minority of patients will develop $\mathrm{PH}$ postoperatively with a chronically increased PVR and PHVD later, when shunt closure occurs early in life (7). However, patients, who develop PH, sometimes even decades after corrective surgery, have been shown to have a significantly increased mortality risk $(2,7,8)$.

\section{Implications of new definition}

A change of definition of a disease raises the question, 
if this results in a change of the therapeutic approach, particularly for asymptomatic patients. Not only the indication, but also the economic burden and potential associated adverse effects of the drugs have to be taken into account (7).

Due to scarcity of randomized controlled studies, evidence-based therapeutic strategies in children with $\mathrm{PH}$ are lacking and experience if often adopted from adult practice. In addition, there is a lack of licensed advanced therapeutic drugs for the use in children. Hence offlabel therapy is often used in children, in analogy to other pediatric subspecialties (9).

In contrast to the longest available vasodilators, the calcium-channel-blockers, the-so called-'advanced medical therapies' do not only have vasodilatory effects, but are also thought to have anti-proliferative properties and hence may slow down disease progression and vascular remodeling processes that lead to PHVD.

To date there is no evidence for an improved outcome or hemodynamic improvement with the use of advanced anti-pulmonary hypertensive therapies with only a mildly elevated mPAP of 21-24 mmHg.

However, also the previous threshold for the $\mathrm{PH}$ definition of mPAP $\geq 25 \mathrm{mmHg}$ has been an arbitrary choice. All available studies on PAH-drug safety and efficacy have investigated exclusively patients with a mPAP $\geq 25 \mathrm{mmHg}$, according to the former definition. Yet even available pediatric studies were designed enrolling children according to the former definition. Thus, evidence for efficacy, functional or prognostic benefit of advanced therapeutic drugs provide data specifically for those children, who represent a different population.

In our opinion, the use of advanced therapies on the basis of the new definition (mPAP $>20 \mathrm{mmHg}$ ) is questionable. To date, in most children and teenagers with $\mathrm{PH}$ advanced medical therapy is still only warranted if mPAP exceeds $\geq 25 \mathrm{mmHg}$. Indication for treatment, however, should be a patient-tailored decision, depending on $\mathrm{PH}$ etiology and other associated driving factors.

We believe, it is justified, to offer follow-up and screening visits for children and adolescents, who do fulfil the $\mathrm{PH}$ criteria according to the new definition $(10,11)$.

For individual (symptomatic) patients with an only mildly elevated mPAP (21-24 mmHg) and increase of PVRI $\left(\geq 3 \mathrm{WU} \times \mathrm{m}^{2}\right)$ or associated risk factors (e.g., positive genetics and/or family history of severe $\mathrm{PH}$ ), advanced medical therapy may be indicated.
Because of the complexity and heterogeneity of $\mathrm{PH}$ in childhood and adolescence, children should be referred to pediatric cardiology centers, that have $\mathrm{PH}$ expertise. Particularly the indication for PAH specific therapyindependent of clinical severity at presentation-should be initiated there and children should be linked to and seen in $\mathrm{PH}$ specialist clinics. Counselling patients and parents of the implication of the new $\mathrm{PH}$ definition (mPAP $>20 \mathrm{mmHg}$ ) is paramount. To date there are no therapeutic consequences in patients, who may present with mPAPs between 21-24 $\mathrm{mmHg}$ during cardiac catheterization, which formally confirms the diagnosis of $\mathrm{PH}$ according to the new definition.

\section{Conclusions}

The definition of PH has changed in 2018 (WSPH, Nice) to a lower mPAP of $>20 \mathrm{mmHg}$ (rather than $\geq 25 \mathrm{mmHg}$ previously). Because of lacking evidence in children, no changes to currently applied pharmaceutical strategies are warranted to date.

\section{Acknowledgments}

Funding: None.

\section{Footnote}

Provenance and Peer Review: This article was commissioned by the editorial office, Cardiovascular Diagnosis and Therapy for the series "Pediatric Pulmonary Hypertension". The article has undergone external peer review.

Conflicts of Interest: Both authors have completed the ICMJE uniform disclosure form (available at http://dx.doi. org/10.21037/cdt-20-412). The series "Pediatric Pulmonary Hypertension" was commissioned by the editorial office without any funding or sponsorship. Both authors served as the unpaid Guest Editors of the series. AEL received remuneration for advisory consultancy for Actelion, outside the submitted work. CA reports lecture fees from Actelion, outside the submitted work. The authors have no other conflicts of interest to declare.

Ethical Statement: The authors are accountable for all aspects of the work in ensuring that questions related to the accuracy or integrity of any part of the work are 
appropriately investigated and resolved.

Open Access Statement: This is an Open Access article distributed in accordance with the Creative Commons Attribution-NonCommercial-NoDerivs 4.0 International License (CC BY-NC-ND 4.0), which permits the noncommercial replication and distribution of the article with the strict proviso that no changes or edits are made and the original work is properly cited (including links to both the formal publication through the relevant DOI and the license). See: https://creativecommons.org/licenses/by-nc-nd/4.0/.

\section{References}

1. Berger RM, Beghetti M, Humpl T, et al. Clinical features of paediatric pulmonary hypertension: a registry study. Lancet 2012;379:537-46.

2. Hansmann G, Koestenberger M, Alastalo TP, et al. 2019 updated consensus statement on the diagnosis and treatment of pediatric pulmonary hypertension: The European Pediatric Pulmonary Vascular Disease Network (EPPVDN), endorsed by AEPC, ESPR and ISHLT. J Heart Lung Transplant 2019;38:879-901.

3. Simonneau G, Montani D, Celermajer DS, et al. Haemodynamic definitions and updated clinical classification of pulmonary hypertension. Eur Respir J 2019;53:1801913.

4. Rosenzweig EB, Abman SH, Adatia I, et al. Paediatric pulmonary arterial hypertension: updates on definition, classification, diagnostics and management. Eur Respir J 2019;53:1801916.

Cite this article as: Lammers AE, Apitz C. Update from the World Symposium on Pulmonary Hypertension 2018: does the new hemodynamic definition of pediatric pulmonary hypertension have an impact on treatment strategies? Cardiovasc Diagn Ther 2021;11(4):1048-1051. doi: 10.21037/ cdt-20-412
5. Douschan P, Kovacs G, Avian A, et al. Mild Elevation of Pulmonary Arterial Pressure as a Predictor of Mortality. Am J Respir Crit Care Med 2018;197:509-16.

6. Kolte D, Lakshmanan S, Jankowich MD, et al. Mild Pulmonary Hypertension Is Associated With Increased Mortality: A Systematic Review and Meta-Analysis. J Am Heart Assoc 2018;7:e009729.

7. Lammers AE, Bauer LJ, Diller GP, et al. Pulmonary hypertension after shunt closure in patients with simple congenital heart defects. Int J Cardiol 2020;308:28-32.

8. Haworth SG, Hislop AA. Treatment and survival in children with pulmonary arterial hypertension: the UK Pulmonary Hypertension Service for Children 2001-2006. Heart 2009;95:312-7.

9. Hansmann G, Apitz C. Treatment of children with pulmonary hypertension. Expert consensus statement on the diagnosis and treatment of paediatric pulmonary hypertension. The European Paediatric Pulmonary Vascular Disease Network, endorsed by ISHLT and DGPK. Heart 2016;102 Suppl 2:ii67-85.

10. Apitz C, Hansmann G, Schranz D. Hemodynamic assessment and acute pulmonary vasoreactivity testing in the evaluation of children with pulmonary vascular disease. Expert consensus statement on the diagnosis and treatment of paediatric pulmonary hypertension. The European Paediatric Pulmonary Vascular Disease Network, endorsed by ISHLT and DGPK. Heart 2016;102 Suppl 2:ii23-9.

11. Koestenberger M, Hansmann G, Apitz C, et al. Diagnostics in Children and Adolescents with Suspected or Confirmed Pulmonary Hypertension. Paediatr Respir Rev 2017;23:3-15. 